\title{
Advancing Treatment of Pituitary Adenomas through Targeted Molecular Therapies: The Acromegaly and Cushing Disease Paradigms
}

\author{
Michael A. Mooney, Elias D. Simon and Andrew S. Little* \\ Department of Neurosurgery, Barrow Neurological Institute, St. Joseph's Hospital and Medical Center, Phoenix, AZ, USA
}

\section{OPEN ACCESS}

Edited by:

Ziya Levent Gokaslan, Brown University, USA

Reviewed by: Manish Singh Sharma, Mayo Clinic Health System, USA Amgad Hanna, University of Wisconsin-Madison, USA Leonardo Welling, Ponta Grossa State University, Brazil

${ }^{*}$ Correspondence: Andrew S. Little neuropub@dignityhealth.org

Specialty section: This article was submitted to Neurosurgery, a section of the journa

Frontiers in Surgery

Received: 31 March 2016 Accepted: 12 July 2016

Published: 28 July 2016

Citation:

Mooney MA, Simon ED and Little AS (2016) Advancing Treatment of Pituitary Adenomas through Targeted Molecular Therapies: The Acromegaly and Cushing Disease Paradigms.

Front. Surg. 3:45. doi: 10.3389/fsurg.2016.00045
The current treatment of pituitary adenomas requires a balance of conservative management, surgical resection, and in select tumor types, molecular therapy. Acromegaly treatment is an evolving field where our understanding of molecular targets and drug therapies has improved treatment options for patients with excess growth hormone levels. We highlight the use of molecular therapies in this disease process and advances in this field, which may represent a paradigm shift for the future of pituitary adenoma treatment.

Keywords: acromegaly, Cushing disease, endonasal, pituitary adenoma, transsphenoidal

\section{INTRODUCTION}

Pituitary adenomas make up more than $90 \%$ of all pituitary tumors and are the second most commonly diagnosed non-malignant brain tumors (1). The clinical presentation of patients with pituitary adenomas is highly variable and often depends on the endocrinologic function of the tumor, the size of the tumor, or a combination of both. Given the increased use of neuroimaging studies over the past decade, a significant number of pituitary lesions are incidentally found, and the prevalence of pituitary tumors in the general population is estimated to be around $17 \%$ (2). The heterogeneity of clinical presentations combined with the relatively high prevalence of "incidentalomas" poses a diagnostic challenge to providers treating these patients, and multidisciplinary teams consisting of endocrinologists, neuro-ophthalmologists, and neurosurgeons have proven essential for delivering the highest quality of care.

Distinguishing a functional (i.e., hormone-secreting) from a non-functional adenoma is crucial for guiding subsequent treatment strategies. Although surgical resection remains the mainstay of therapy for macroadenomas causing compression of neurovascular structures, as well as for many functional microadenomas, pharmacotherapy can play a crucial role in adenoma treatment. Recent advances in genetic and molecular analysis of pituitary adenomas have provided new insights into the growth patterns and secretory functions of these tumors and have allowed for a more precise characterization of individual adenomas. These advances have led to the development of targeted molecular therapies for several subtypes of pituitary adenoma and the development of a

Abbreviations: ACTH, adrenocorticotropic hormone; DR, dopamine receptor; GH, growth hormone; IGF, insulin-like growth factor; OGTT, oral glucose tolerance test. 
"personalized" approach to pharmacotherapy for some patients with adenomas.

Acromegaly is one pituitary disease where recent and ongoing research has changed the standard treatment paradigm. Although pharmacotherapy has not replaced surgical resection as the mainstay of treatment, exciting advances in targeted molecular therapies have developed in recent years. We can currently implement individualized treatment options for patients with acromegaly, and the potential of this strategy is immense as our understanding of the molecular pathology of these tumors progresses. We believe that the combined surgical, targeted pharmacotherapeutic, and radiosurgical approach that is employed in acromegaly represents a paradigm that will continue to improve the treatment of not only growth hormone $(\mathrm{GH})$-secreting adenomas but also other functional and nonfunctional adenomas.

In this review, we highlight the current literature on the diagnosis and treatment of acromegaly with an emphasis on current targeted molecular therapies. We also review emerging treatment paradigms for Cushing disease that parallel this approach, and we discuss future directions for this exciting field.

\section{GROWTH HORMONE-SECRETING ADENOMAS}

\section{Overview}

Growth hormone-secreting pituitary adenomas manifest as the clinical syndrome acromegaly, which is a chronic disorder that results in acral overgrowth, cardiovascular disease, insulin resistance, arthritis, and sleep apnea, among other conditions (3). In children harboring a $\mathrm{GH}$-secreting adenoma, excess $\mathrm{GH}$ production before closure of the epiphyseal plates leads to gigantism. Given the widespread effects of GH overproduction, as well as the often indolent physiologic changes in an individual patient, the diagnosis of acromegaly is often delayed. If untreated, acromegaly results in significant morbidity and increased rates of mortality for these patients (4).

The current diagnosis of acromegaly is dependent upon both the oral glucose tolerance test (OGTT) and serum levels of insulin-like growth factor-1 (IGF-1). A decline in GH production after an oral glucose load is present in normal patients, and this decrease is diminished in patients with acromegaly; detailed criteria have been established for utilizing this diagnostic tool to help identify patients with acromegaly (5). Additionally, serum IGF-1 levels are elevated in patients with acromegaly because of increased production from the liver. Circulating $\mathrm{GH}$ binds $\mathrm{GH}$ receptors on hepatocytes and activates a signaling cascade, resulting in increased in IGF1 transcription, translation, and IGF-1 secretion (3). IGF-1 levels adequate for diagnosis are dependent on sex and age, and established values have been outlined (5-9). IGF-1 exerts effects on numerous target tissues throughout the body, and stimulation via this growth factor contributes to the increased morbidity and mortality encountered in patients with acromegaly (4).

Surgical resection is the mainstay of treatment for acromegaly caused by a $\mathrm{GH}$-secreting adenoma. However, not all patients are candidates for surgery, and not all adenomas are amenable to complete resection. Since surgical treatment is not always an option, a large role for both pharmacotherapy and stereotactic radiosurgery has developed in this population of patients. An improved molecular understanding of pituitary adenomas has advanced pharmacologic options for acromegaly patients, and we hypothesize that this is the start of a paradigm shift in the treatment of acromegaly. In this article, we review the literature on surgical success rates and targeted molecular therapies in acromegaly. Radiosurgery success rates and expert opinions on the implementation of this strategy have been reviewed elsewhere (10-12).

\section{Surgical Treatment}

Surgical success rates in the literature vary widely depending on tumor size, the degree of invasion, surgeon experience, adjuvant therapies, and definition of success (i.e., laboratory values defined as curative). When examining the success of surgery alone, the largest series as of 2016 examined 688 patients with acromegaly treated at a single center (13). Criteria required to define a cure included normalization of basal GH to $<2.5 \mathrm{ng} / \mathrm{L}$, suppression of $\mathrm{GH}$ to $<1 \mathrm{ng} / \mathrm{L}$ during the OGTT, and IGF-I normal for age and sex, which are the current standard definitions for biochemical remission. The overall remission rate for all tumors treated via the transsphenoidal approach was $57.3 \%$ at the 3 -month follow-up in this study. Of note, success varied widely based on tumor size and invasion characteristics, with $75.3 \%$ of microadenomas surgically in remission versus $41.5 \%$ of macroadenomas with parasellar or sphenoidal extension. In this series, only two patients with surgical remission developed recurrent acromegaly within a mean follow-up of 10 or more years.

Numerous smaller series in the literature largely support these values, with surgical remission rates ranging to $60 \%$ (14-20). Reported recurrence rates in the literature to date vary widely due to the different criteria for biochemical remission and varying years of follow-up; recurrence rates ranging from 0.4 to $19 \%$ $(7,13,17,21-23)$ are reported, with one 2012 meta-analysis citing a mean $6 \%$ recurrence rate within 10 years $(20)$.

\section{Targeted Molecular Therapies}

For the subset of acromegaly patients without biochemical remission after surgery, or for those patients who are unable or unwilling to undergo surgery, pharmacotherapy takes on an essential role. Pharmacotherapy for acromegaly was first used in the 1970s, and our understanding of $\mathrm{GH}$-secreting adenomas has significantly advanced since that time (24). With a better understanding of the molecular biology of GH-secreting cells, the introduction of more targeted therapies has been possible, and we can now better tailor pharmacotherapy regimens for individual patients with acromegaly.

The population of cells within the anterior pituitary gland that secrete GH were identified in the early twentieth century in association with acromegaly and became known as somatotroph cells (24). Like other cell types of the anterior pituitary gland, somatotroph cells typically remain under tight physiologic control through positive and negative feedback from the hypothalamus. 
Somatotroph cells express two classes of receptors that mediate negative feedback - dopamine receptors (DRs) and somatostatin receptors. Both pathways have been successfully targeted pharmacologically and with a resultant decrease in GH secretion in patients with acromegaly. A third pathway, the $\mathrm{GH}$ receptor pathway, has also been successfully targeted for acromegaly pharmacotherapy. All three pathways are reviewed here.

Dopamine receptors are encoded by five separate genes (DRD1-DRD5). However, DRD2 and DRD4 are the two genes predominantly expressed in the normal pituitary gland (25). DRD2 is strongly expressed in both somatotrophs and lactotrophs, and binding of dopamine (or dopamine agonist medications) to DRD2 triggers an inhibitory signaling cascade to decrease prolactin secretion. DRs were first targeted in the 1970s with the dopamine agonist bromocriptine; however, the dopamine agonist cabergoline has since proven to be more effective due to its increased DR2 selectivity and longer half life $(26,27)$. Interestingly, DR2 expression levels in somatotrophs are correlated with dopamine agonist response rates both in vitro and in vivo, and analysis of prolactin and DR2 expression patterns within $\mathrm{GH}$-secreting adenomas has been proposed as a guide for pharmacotherapy strategies in acromegaly patients (28-31). Furthermore, dopamine agonists are recommended for adenomas that secrete both GH and prolactin if pharmacotherapy is needed after surgery because both expression pathways are targeted by these agents (32).

Somatostatin receptors are also encoded by five separate genes (SSTR1-SSTR5), and the SSTR2 and SSTR5 subtypes make up 90-95\% of receptor expression in GH-secreting adenomas (33). SSTR expression is found within normal pituitary cells including corticotrophs and lactotrophs, and binding of somatostatin to SSTRs triggers a G-protein-mediated signal cascade that inhibits secretory function in these cells. The two standard somatostatin analogs in use today are octreotide and lanreotide, which activate this signaling pathway to inhibit hormone production in functional adenomas. There is significant heterogeneity in clinical responsiveness to these agents, and recent research suggests this may be due to heterogeneous SSTR subtype expression between patients $(34,35)$. More recently, the somatostatin analog pasireotide was developed, which has increased binding affinity for SSTR2 and SSTR5 compared to octreotide and lanreotide. Pasireotide has shown superior efficacy for biochemical control in some studies of patients with acromegaly (36). This drug class is one example of how an improved molecular understanding of somatotrophs may provide more efficacious treatment options for patients with acromegaly; however, further studies are required before receptor expression profiles can be used to guide clinical practice.

The class of GH-receptor antagonists is the third and final example of successful targeted molecular therapy in acromegaly. $\mathrm{GH}$ receptors are found primarily in the liver and cartilage where activation triggers the JAK-STAT (Janus kinase/signal transducers and activators of transcription) pathway and ultimately leads to upregulation in cell proliferation and antiapoptotic proteins, including IGF-1 (3). Pegvisomant is currently the only GH-receptor antagonist approved by the U.S. Food and Drug Administration that is available for treatment of acromegaly, and it is a pegylated analog of human $\mathrm{GH}$, which directly competes for receptor binding with plasma $\mathrm{GH}$ (37). Binding of pegvisomant prevents dimerization of the GH-receptor and thereby blocks the signaling cascade, resulting in decreased IGF-1 production. Of note, this mechanism is significantly different from that of the dopamine and somatostatin analogs, because it blocks the downstream effects of a GH-secreting adenoma, independent of tumor receptor expression patterns $(3,38)$. Use of pegvisomant is typically reserved for patients in whom treatment with somatostatin analogs fails or in patients with diabetes mellitus $(32,39)$.

\section{Current and Future Clinical Practice}

Complete surgical resection of a $\mathrm{GH}$-secreting adenoma remains the first-line treatment option for acromegaly today. Surgical cure rates are high, with low morbidity and mortality when surgery is performed at a center with an experienced neurosurgical team as the first-line treatment for eligible patients. In patients with persistent or recurrent disease after surgery, or those unable to or unwilling to undergo surgery, pharmacotherapy and stereotactic radiosurgery remain excellent treatment options. Several pathways of pharmacotherapy for acromegaly have been evaluated, including use as adjuvant therapy (following surgery), as neoadjuvant therapy (before surgery), and as primary therapy (in place of surgery). The efficacy and implementation of stereotactic radiosurgery for functional pituitary adenomas have been extensively reviewed elsewhere (10-12).

Numerous studies have evaluated the efficacy of pharmacotherapy for persistent or recurrent disease after surgical resection, and somatostatin analogs are considered first-line therapy for these patients (40). It is estimated that approximately $30-60 \%$ of patients with persistent disease after surgical resection achieve biochemical remission with the addition of a somatostatin analog (41-44). An additional percentage of patients achieve biochemical remission with dopamine agonists, pegvisomant, or combination therapy with these agents. Radiological follow-up in these patients must be interpreted with caution. Tumor shrinkage is often observed with postoperative somatostatin analog treatment, but, this does not reliably correlate with biochemical remission $(42,45)$. Notably, some studies have noted correlations in somatostatin and dopamine expression patterns in the adenoma with treatment response, which may allow for a more individualized approach to pharmacotherapy strategies in these patients in the future $(2,29,30,34,35,46-49)$. GH and IGF-1 must be closely monitored in patients with known residual tumor undergoing adjuvant treatment, and treatment strategies for recurrent disease must be made on a case-by-case basis.

Neoadjuvant therapy with somatostatin analogs has been attempted in patients with large GH-secreting adenomas with some success. Preoperative treatment with somatostatin analogs was investigated in multiple studies of macroadenomas secreting $\mathrm{GH}$, and this regimen was consistently shown to decrease tumor volume and $\mathrm{GH}$ secretion levels in patients prior to surgery (50). Additionally, short-term biochemical remission rates (3-4 months postoperatively) were consistently improved with neoadjuvant therapy. However, this effect was not clearly 
demonstrated for long-term remission rates, and further studies on this subject remain to be performed. Although preoperative somatostatin analogs may decrease tumor volume, they do not convert unresectable, invasive tumors into resectable lesions. We believe this may limit the success of this strategy going forward, and preoperative somatostatin analogs should be given only to a small subset of carefully selected patients.

Since their introduction, the success of monotherapy with somatostatin analogs for some patients has been the most impressive contribution of pharmacotherapy for acromegaly. Recent studies have demonstrated good biochemical control with such treatment $(36,51-53)$. When interpreting biochemical control data, it is important to consider whether the patient population was preselected for somatostatin responsiveness and what other treatments the patients have received. The published remission rates for somatostatin analogs have declined as more experience is gained with the drugs because of the increased recognition of these two factors. Although most studies to date have focused on octreotide or lanreotide monotherapy, we hypothesize that future studies investigating new-generation somatostatin analogs, such as pasireotide, could demonstrate superior results. Preliminary studies with pasireotide show significantly higher rates of biochemical control compared with octreotide $(36,54)$.

At our institution, we attempt complete resection as the firstline treatment. In patients with residual disease not amenable to further resection (and with elevated GH and IGF-1 levels postoperatively), adjuvant somatostatin analog therapy is initiated, and patients are monitored for their biochemical response. Concurrent adjuvant radiosurgery with somatostatin analog treatment is provided on a case-by-case basis considering the location and volume of the residual tumor.

As our molecular understanding of somatotrophs advances and drugs are developed to target new sites, the role for pharmacotherapy in acromegaly will continue to expand. Although surgical resection remains the mainstay of treatment today, the future likely holds a shift in our treatment paradigm to one that emphasizes pharmacotherapy (Figure 1). Personalized approaches to pharmacotherapy for acromegaly may emerge based on molecular expression profiles of individual patient tumors; however, future research on this subject is required before it can be used to guide treatment for patients with acromegaly.

\section{OTHER FUNCTIONAL ADENOMAS}

\section{Cushing Disease}

Adrenocorticotropic hormone (ACTH)-secreting pituitary adenomas manifest as the clinical syndrome of Cushing disease. Excessive secretion of ACTH leads to hypercortisolemia, and these patients present with widespread clinical symptoms including central obesity, facial plethora, amenorrhea, and skin changes, among many others. Surgical resection of the ACTH-secreting adenoma is currently the mainstay of treatment for patients with Cushing disease. However, as with acromegaly, the role for pharmacotherapy in treated Cushing disease is growing. As our molecular understanding of this disease progresses, drug development continues to produce new treatment options for patients with persistent or recurrent disease after surgery, as well as for those patients unable or unwilling to undergo surgery.

Today, the rate of postoperative biochemical remission following surgical resection of microadenomas is approximately $75 \%$ while remission of macroadenomas is about $43 \%$ (55-57). For the remainder of patients and for those who do not undergo surgery, the addition of pharmacotherapy plays a crucial role in treatment. Pharmacotherapy of Cushing disease targets three main pathways: central secretory action at the level of the pituitary, steroidogenesis, and end-target action at the glucocorticoid receptor (58). As with acromegaly, increasing knowledge of corticotroph receptor expression has guided medical treatment options for this disease.

Corticotrophs express high levels of SSTR5 and DRD2, similar to the expression seen in somatotrophs (59). Pharmacotherapy targets these receptors using somatostatin ligands and dopamine agonists, respectively, to decrease ACTH production by corticotroph adenomas. Pasireotide, in particular, has demonstrated efficacy in patients with Cushing disease due to its relatively high

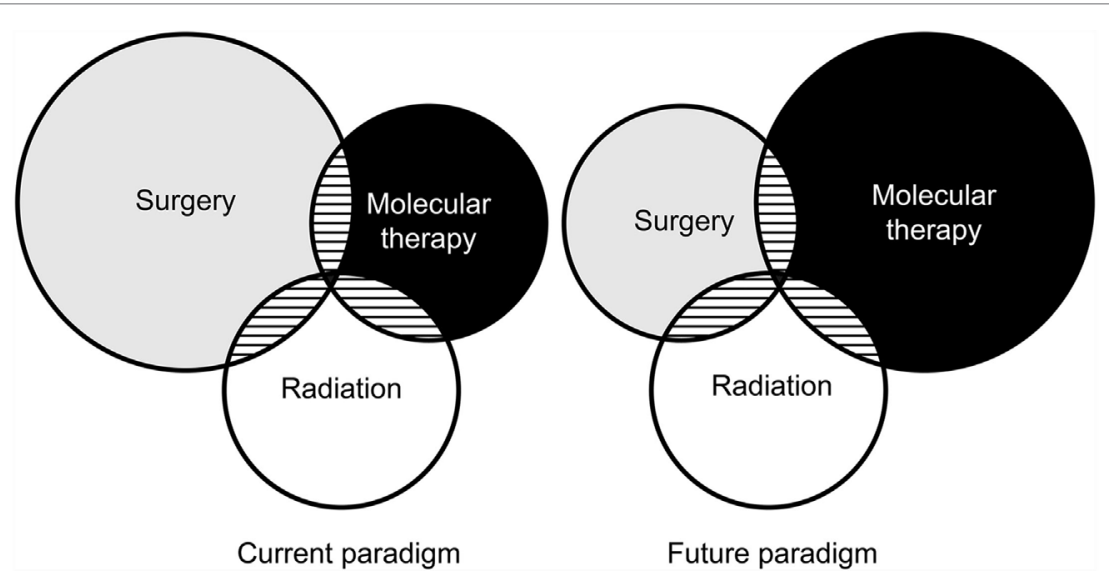

FIGURE 1 | Venn diagram illustrating the relative impact of antitumor treatments in acromegaly as practiced today and what it might look like in the future. Used with permission from Barrow Neurological Institute, Phoenix, Arizona. 
binding affinity for SSTR5 (60). Phase II and III clinical trials utilizing pasireotide in patients who have not undergone surgery have demonstrated a significant reduction in urinary free cortisol levels, as well as improvement in symptoms of hypercortisolemia (61). A large, randomized, double-blind, multicenter, phase III study is currently underway to evaluate pasireotide as monotherapy for this group of patients. Cabergoline is also used in the medical management of Cushing disease by targeting corticotroph secretory function. Several trials have demonstrated its efficacy both in vitro and in vivo (62-64). In non-responders or partial responders to a single agent, combination therapy with pasireotide and cabergoline, was shown to be effective in decreasing urinary free cortisol levels (65). Other somatostatin analogs and dopamine agonists (octreotide, lanreotide, and bromocriptine) are not as effective in Cushing disease as they are in acromegaly, and these agents are not routinely used in clinical practice today.

Ketoconazole and metyrapone are the most widely used steroidogenesis inhibitors prescribed today for refractory Cushing syndrome; however, no prospective studies have evaluated these agents in Cushing disease, and their use is currently off-label (66). Investigations into alternative steroidogenesis targets are ongoing and may hold future promise (67). Mifepristone is the only current glucocorticoid receptor antagonist available for use in Cushing disease, and it is Food and Drug Administration approved for treatment of hyperglycemia in Cushing syndrome (61). It has demonstrated efficacy in long-term symptom resolution in a multicenter trial (68); however, its use is contraindicated in pregnant women, and it may be associated with adenoma enlargement (69). Serial magnetic resonance imaging is warranted to monitor for such enlargement in patients with Cushing disease treated with mifepristone.

Although numerous pharmacologic targets exist in Cushing disease, medical management has yet to reach the efficacy and safety of surgery; transsphenoidal resection remains the treatment of choice for eligible patients with an ACTH-secreting

\section{REFERENCES}

1. Ostrom QT, Gittleman H, Fulop J, Liu M, Blanda R, Kromer C, et al. CBTRUS Statistical Report: primary brain and central nervous system tumors diagnosed in the United States in 2008-2012. Neuro Oncol (2015) 17(Suppl 4):iv1-62. doi:10.1093/neuonc/nov189

2. Ezzat S, Asa SL, Couldwell WT, Barr CE, Dodge WE, Vance ML, et al. The prevalence of pituitary adenomas: a systematic review. Cancer (2004) 101(3):613-9. doi:10.1002/cncr.20412

3. Manjila S, Wu OC, Khan FR, Khan MM, Arafah BM, Selman WR. Pharmacological management of acromegaly: a current perspective. Neurosurg Focus (2010) 29(4):E14. doi:10.3171/2010.7.FOCUS 10168

4. Melmed S. Medical progress: acromegaly. N Engl J Med (2006) 355(24):255873. doi:10.1056/NEJMra062453

5. Katznelson L, Atkinson JL, Cook DM, Ezzat SZ, Hamrahian AH, Miller KK. American Association of Clinical Endocrinologists Medical Guidelines for Clinical Practice for the Diagnosis and Treatment of Acromegaly - 2011 update: executive summary. Endocr Pract (2011) 17(4):636-46. doi:10.4158/ EP.17.4.636

6. Brabant G. Insulin-like growth factor-I: marker for diagnosis of acromegaly and monitoring the efficacy of treatment. Eur J Endocrinol (2003) 148(Suppl 2):S15-20. doi:10.1530/eje.0.148S015 adenoma. Similar to acromegaly, an improved understanding of the molecular basis of corticotroph cells and end-target receptors will continue to spur drug development and improve medical treatment options for this challenging disease.

\section{CONCLUSION AND FUTURE DIRECTIONS}

Pituitary adenomas are relatively common tumors, and transsphenoidal resection is a safe and effective treatment option for many of these lesions. Surgical resection by an experienced pituitary surgeon remains the mainstay of therapy for both acromegaly and Cushing disease. However, a significant percentage of patients have persistent or recurrent disease after surgery or are not surgical candidates. An improved understanding of the molecular biology of these diseases has evolved since the mid1970s, and targeted molecular therapies that limit the growth, secretory function, and end-organ effects of these tumors continue to be developed. The greatest success has come with the class of somatostatin analogs, and new knowledge regarding receptor subtype expression in pituitary adenomas has helped guide treatment strategies. Further research into this domain may allow for more individualized treatment strategies for patients harboring tumors with expression patterns that can be characterized. Although some research has supported this approach to date, further studies are required before this paradigm can be applied outside of academic pituitary practices. Characterization of tumor expression patterns is a challenging task, but we believe that targeted pharmacotherapy could approach, and eventually surpass, the efficacy of surgical resection for the treatment of these lesions.

\section{AUTHOR CONTRIBUTIONS}

All authors have made substantial, direct, and intellectual contributions to the work and approved it for publication.

7. Freda PU. Current concepts in the biochemical assessment of the patient with acromegaly. Growth Horm IGF Res (2003) 13(4):171-84. doi:10.1016/ S1096-6374(03)00029-7

8. Subbarayan SK, Fleseriu M, Gordon MB, Brzana JA, Kennedy L, Faiman C, et al. Serum IGF-1 in the diagnosis of acromegaly and the profile of patients with elevated IGF-1 but normal glucose-suppressed growth hormone. Endocr Pract (2012) 18(6):817-25. doi:10.4158/EP11324.OR

9. Colao A, Auriemma RS, Pivonello R, Kasuki L, Gadelha MR. Interpreting biochemical control response rates with first-generation somatostatin analogues in acromegaly. Pituitary (2016) 19(3):235-47. doi:10.1007/s11102-015-0684-z

10. Stapleton CJ, Liu CY, Weiss $\mathrm{MH}$. The role of stereotactic radiosurgery in the multimodal management of growth hormone-secreting pituitary adenomas. Neurosurg Focus (2010) 29(4):E11. doi:10.3171/2010.7.FOCUS10159

11. Jagannathan J, Yen CP, Pouratian N, Laws ER, Sheehan JP. Stereotactic radiosurgery for pituitary adenomas: a comprehensive review of indications, techniques and long-term results using the Gamma Knife.J Neurooncol (2009) 92(3):345-56. doi:10.1007/s11060-009-9832-5

12. Lee CC, Vance ML, Lopes MB, Xu Z, Chen CJ, Sheehan J. Stereotactic radiosurgery for acromegaly: outcomes by adenoma subtype. Pituitary (2015) 18(3):326-34. doi:10.1007/s11102-014-0578-5

13. Nomikos P, Buchfelder M, Fahlbusch R. The outcome of surgery in 668 patients with acromegaly using current criteria of biochemical 'cure'. Eur J Endocrinol (2005) 152(3):379-87. doi:10.1530/eje.1.01863 
14. Starke RM, Raper DM, Payne SC, Vance ML, Oldfield EH, Jane JA Jr. Endoscopic vs microsurgical transsphenoidal surgery for acromegaly: outcomes in a concurrent series of patients using modern criteria for remission. J Clin Endocrinol Metab (2013) 98(8):3190-8. doi:10.1210/jc.2013-1036

15. Shin SS, Tormenti MJ, Paluzzi A, Rothfus WE, Chang YF, Zainah H, et al. Endoscopic endonasal approach for growth hormone secreting pituitary adenomas: outcomes in 53 patients using 2010 consensus criteria for remission. Pituitary (2013) 16(4):435-44. doi:10.1007/s11102-012-0440-6

16. Wang YY, Higham C, Kearney T, Davis JR, Trainer P, Gnanalingham KK. Acromegaly surgery in Manchester revisited - the impact of reducing surgeon numbers and the 2010 consensus guidelines for disease remission. Clin Endocrinol (2012) 76(3):399-406. doi:10.1111/j.1365-2265.2011.04193.x

17. Roelfsema F, Biermasz NR, Pereira AM. Clinical factors involved in the recurrence of pituitary adenomas after surgical remission: a structured review and meta-analysis. Pituitary (2012) 15(1):71-83. doi:10.1007/s11102-011-0347-7

18. Hofstetter CP, Shin BJ, Mubita L, Huang C, Anand VK, Boockvar JA, et al. Endoscopic endonasal transsphenoidal surgery for functional pituitary adenomas. Neurosurg Focus (2011) 30(4):E10. doi:10.3171/2011.1.FOCUS10317

19. Campbell PG, Kenning E, Andrews DW, Yadla S, Rosen M, Evans JJ. Outcomes after a purely endoscopic transsphenoidal resection of growth hormone-secreting pituitary adenomas. Neurosurg Focus (2010) 29(4):E5. doi:10.3171/2010.7.FOCUS10153

20. Marko NF, LaSota E, Hamrahian AH, Weil RJ. Comparative effectiveness review of treatment options for pituitary microadenomas in acromegaly. J Neurosurg (2012) 117(3):522-38. doi:10.3171/2012.4.JNS11739

21. Freda PU, Wardlaw SL, Post KD. Long-term endocrinological follow-up evaluation in 115 patients who underwent transsphenoidal surgery for acromegaly. J Neurosurg (1998) 89(3):353-8. doi:10.3171/jns.1998.89.3.0353

22. Biermasz NR, van Dulken H, Roelfsema F. Ten-year follow-up results of transsphenoidal microsurgery in acromegaly. J Clin Endocrinol Metab (2000) 85(12):4596-602. doi:10.1210/jcem.85.12.7042

23. Mathioudakis N, Salvatori R. Management options for persistent postoperative acromegaly. Neurosurg Clin N Am (2012) 23(4):621-38. doi:10.1016/j. nec.2012.06.005

24. de Herder WW. The history of acromegaly. Neuroendocrinology (2016) 103(1):7-17. doi:10.1159/000371808

25. Neto LV, Machado Ede O, Luque RM, Taboada GF, Marcondes JB, Chimelli LM, et al. Expression analysis of dopamine receptor subtypes in normal human pituitaries, nonfunctioning pituitary adenomas and somatotropinomas, and the association between dopamine and somatostatin receptors with clinical response to octreotide-LAR in acromegaly. J Clin Endocrinol Metab (2009) 94(6):1931-7. doi:10.1210/jc.2008-1826

26. Abs R, Verhelst J, Maiter D, Van Acker K, Nobels F, Coolens JL, et al. Cabergoline in the treatment of acromegaly: a study in 64 patients. JClin Endocrinol Metab (1998) 83(2):374-8. doi:10.1210/jcem.83.2.4556

27. Moyes VJ, Metcalfe KA, Drake WM. Clinical use of cabergoline as primary and adjunctive treatment for acromegaly. Eur J Endocrinol (2008) 159(5):541-5. doi:10.1530/EJE-08-0306

28. Colao A, Ferone D, Marzullo P, Di Sarno A, Cerbone G, Sarnacchiaro F, et al. Effect of different dopaminergic agents in the treatment of acromegaly. J Clin Endocrinol Metab (1997) 82(2):518-23. doi:10.1210/jcem.82.2.3648

29. Saveanu A, Jaquet P, Brue T, Barlier A. Relevance of coexpression of somatostatin and dopamine D2 receptors in pituitary adenomas. Mol Cell Endocrinol (2008) 286(1-2):206-13. doi:10.1016/j.mce.2007.12.008

30. Saveanu A, Gunz G, Guillen S, Dufour H, Culler MD, Jaquet P. Somatostatin and dopamine-somatostatin multiple ligands directed towards somatostatin and dopamine receptors in pituitary adenomas. Neuroendocrinology (2006) 83(3-4):258-63. doi:10.1159/000095536

31. Ferone D, de Herder WW, Pivonello R, Kros JM, van Koetsveld PM, de Jong T, et al. Correlation of in vitro and in vivo somatotropic adenoma responsiveness to somatostatin analogs and dopamine agonists with immunohistochemical evaluation of somatostatin and dopamine receptors and electron microscopy. J Clin Endocrinol Metab (2008) 93(4):1412-7. doi:10.1210/jc.2007-1358

32. Fleseriu M, Delashaw JB Jr, Cook DM. Acromegaly: a review of current medical therapy and new drugs on the horizon. Neurosurg Focus (2010) 29(4):E15. doi:10.3171/2010.7.FOCUS10154

33. Bronstein MD. Acromegaly: molecular expression of somatostatin receptor subtypes and treatment outcome. Front Horm Res (2006) 35:129-34. doi:10.1159/000094315
34. Bhayana S, Booth GL, Asa SL, Kovacs K, Ezzat S. The implication of somatotroph adenoma phenotype to somatostatin analog responsiveness in acromegaly. J Clin Endocrinol Metab (2005) 90(11):6290-5. doi:10.1210/ jc.2005-0998

35. Casarini AP, Jallad RS, Pinto EM, Soares IC, Nonogaki S, Giannella-Neto D, et al. Acromegaly: correlation between expression of somatostatin receptor subtypes and response to octreotide-lar treatment. Pituitary (2009) 12(4):297303. doi:10.1007/s11102-009-0175-1

36. Colao A, Bronstein MD, Freda P, Gu F, Shen CC, Gadelha M, et al. Pasireotide versus octreotide in acromegaly: a head-to-head superiority study. JClin Endocrinol Metab (2014) 99(3):791-9. doi:10.1210/jc.2013-2480

37. Kopchick JJ, Parkinson C, Stevens EC, Trainer PJ. Growth hormone receptor antagonists: discovery, development, and use in patients with acromegaly. Endocr Rev (2002) 23(5):623-46. doi:10.1210/er.2001-0022

38. van der Lely AJ, Biller BM, Brue T, Buchfelder M, Ghigo E, Gomez R, et al. Long-term safety of pegvisomant in patients with acromegaly: comprehensive review of 1288 subjects in ACROSTUDY. J Clin Endocrinol Metab (2012) 97(5):1589-97. doi:10.1210/jc.2011-2508

39. Melmed S, Colao A, Barkan A, Molitch M, Grossman AB, Kleinberg D, et al. Guidelines for acromegaly management: an update. JClin Endocrinol Metab (2009) 94(5):1509-17. doi:10.1210/jc.2008-2421

40. Giustina A, Chanson P, Kleinberg D, Bronstein MD, Clemmons DR, Klibanski A, et al. Expert consensus document: a consensus on the medical treatment of acromegaly. Nat Rev Endocrinol (2014) 10(4):243-8. doi:10.1038/ nrendo.2014.21

41. Colao A, Attanasio R, Pivonello R, Cappabianca P, Cavallo LM, Lasio G, et al. Partial surgical removal of growth hormone-secreting pituitary tumors enhances the response to somatostatin analogs in acromegaly. J Clin Endocrinol Metab (2006) 91(1):85-92. doi:10.1210/jc.2005-1208

42. Tutuncu Y, Berker D, Isik S, Ozuguz U, Akbaba G, Kucukler FK, et al. Comparison of octreotide LAR and lanreotide autogel as post-operative medical treatment in acromegaly. Pituitary (2012) 15(3):398-404. doi:10.1007/ s11102-011-0335-y

43. Petrossians P, Borges-Martins L, Espinoza C, Daly A, Betea D, Valdes-Socin H, et al. Gross total resection or debulking of pituitary adenomas improves hormonal control of acromegaly by somatostatin analogs. Eur J Endocrinol (2005) 152(1):61-6. doi:10.1530/eje.1.01824

44. Shanik MH, Cao PD, Ludlam WH. Historical response rates of somatostatin analogues in the treatment of acromegaly: a systematic review. Endocr Pract (2015) 22(3):350-6. doi:10.4158/EP15913.RA

45. Amato G, Mazziotti G, Rotondi M, Iorio S, Doga M, Sorvillo F, et al. Longterm effects of lanreotide SR and octreotide LAR on tumour shrinkage and GH hypersecretion in patients with previously untreated acromegaly. Clin Endocrinol (2002) 56(1):65-71. doi:10.1046/j.0300-0664.2001.01438.x

46. Brzana J, Yedinak CG, Gultekin SH, Delashaw JB, Fleseriu M. Growth hormone granulation pattern and somatostatin receptor subtype $2 \mathrm{~A}$ correlate with postoperative somatostatin receptor ligand response in acromegaly: a large single center experience. Pituitary (2013) 16(4):490-8. doi:10.1007/ s11102-012-0445-1

47. Gadelha MR, Kasuki L, Korbonits M. Novel pathway for somatostatin analogs in patients with acromegaly. Trends Endocrinol Metab (2013) 24(5):238-46. doi:10.1016/j.tem.2012.11.007

48. Gatto F, Feelders RA, van der Pas R, Kros JM, Waaijers M, Sprij-Mooij D, et al. Immunoreactivity score using an anti-sst2A receptor monoclonal antibody strongly predicts the biochemical response to adjuvant treatment with somatostatin analogs in acromegaly. J Clin Endocrinol Metab (2013) 98(1):E66-71. doi:10.1210/jc.2012-2609

49. Fleseriu M. Advances in the pharmacotherapy of patients with acromegaly. Discov Med (2014) 17(96):329-38.

50. Fleseriu M, Hoffman AR, Katznelson L; AACE Neuroendocrine and Pituitary Scientific Committee. American Association of Clinical Endocrinologists and American College of Endocrinology Disease State Clinical Review: management of acromegaly patients: what is the role of pre-operative medical therapy? Endocr Pract (2015) 21(6):668-73. doi:10.4158/EP14575. DSCR

51. Abu Dabrh AM, Mohammed K, Asi N, Farah WH, Wang Z, Farah MH, et al. Surgical interventions and medical treatments in treatment-naive patients with acromegaly: systematic review and meta-analysis. JClin Endocrinol Metab (2014) 99(11):4003-14. doi:10.1210/jc.2014-2900 
52. Colao A, Cappabianca P, Caron P, De Menis E, Farrall AJ, Gadelha MR, et al. Octreotide LAR vs. surgery in newly diagnosed patients with acromegaly: a randomized, open-label, multicentre study. Clin Endocrinol (2009) 70(5):75768. doi:10.1111/j.1365-2265.2008.03441.x

53. Petersenn S, Buchfelder M, Reincke M, Strasburger CM, Franz H, Lohmann R, et al. Results of surgical and somatostatin analog therapies and their combination in acromegaly: a retrospective analysis of the German Acromegaly Register. Eur J Endocrinol (2008) 159(5):525-32. doi:10.1530/EJE-08-0498

54. Sheppard M, Bronstein MD, Freda P, Serri O, De Marinis L, Naves L, et al. Pasireotide LAR maintains inhibition of GH and IGF-1 in patients with acromegaly for up to 25 months: results from the blinded extension phase of a randomized, double-blind, multicenter, phase III study. Pituitary (2015) 18(3):385-94. doi:10.1007/s11102-014-0585-6

55. Nieman LK, Ilias I. Evaluation and treatment of Cushing's syndrome. Am J Med (2005) 118(12):1340-6. doi:10.1016/j.amjmed.2005.01.059

56. Chen JC, Amar AP, Choi S, Singer P, Couldwell WT, Weiss MH. Transsphenoidal microsurgical treatment of Cushing disease: postoperative assessment of surgical efficacy by application of an overnight low-dose dexamethasone suppression test. J Neurosurg (2003) 98(5):967-73. doi:10.3171/ jns.2003.98.5.0967

57. Kelly DF. Transsphenoidal surgery for Cushing's disease: a review of success rates, remission predictors, management of failed surgery, and Nelson's syndrome. Neurosurg Focus (2007) 23(3):E5. doi:10.3171/foc.2007.23.3.7

58. Cuevas-Ramos D, Fleseriu M. Treatment of Cushing's disease: a mechanistic update. J Endocrinol (2014) 223(2):R19-39. doi:10.1530/JOE-14-0300

59. de Bruin C, Pereira AM, Feelders RA, Romijn JA, Roelfsema F, Sprij-Mooij DM, et al. Coexpression of dopamine and somatostatin receptor subtypes in corticotroph adenomas. J Clin Endocrinol Metab (2009) 94(4):1118-24. doi:10.1210/jc.2008-2101

60. Bruns C, Lewis I, Briner U, Meno-Tetang G, Weckbecker G. SOM230: a novel somatostatin peptidomimetic with broad somatotropin release inhibiting factor (SRIF) receptor binding and a unique antisecretory profile. Eur J Endocrinol (2002) 146(5):707-16. doi:10.1530/eje.0.1460707

61. Fleseriu M. Medical treatment of Cushing disease: new targets, new hope Endocrinol Metab Clin North Am (2015) 44(1):51-70. doi:10.1016/j. ecl.2014.10.006

62. Pivonello R, De Martino MC, Cappabianca P, De Leo M, Faggiano A, Lombardi G, et al. The medical treatment of Cushing's disease: effectiveness of chronic treatment with the dopamine agonist cabergoline in patients unsuccessfully treated by surgery. J Clin Endocrinol Metab (2009) 94(1):223-30. doi:10.1210/jc.2008-1533

63. Godbout A, Manavela M, Danilowicz K, Beauregard H, Bruno OD, Lacroix A. Cabergoline monotherapy in the long-term treatment of Cushing's disease. Eur J Endocrinol (2010) 163(5):709-16. doi:10.1530/EJE-10-0382

64. Lila AR, Gopal RA, Acharya SV, George J, Sarathi V, Bandgar T, et al. Efficacy of cabergoline in uncured (persistent or recurrent) Cushing disease after pituitary surgical treatment with or without radiotherapy. Endocr Pract (2010) 16(6):968-76. doi:10.4158/EP10031.OR

65. Feelders RA, de Bruin C, Pereira AM, Romijn JA, Netea-Maier RT, Hermus AR, et al. Pasireotide alone or with cabergoline and ketoconazole in Cushing's disease. N Engl J Med (2010) 362(19):1846-8. doi:10.1056/NEJMc1000094

66. Gadelha MR, Vieira Neto L. Efficacy of medical treatment in Cushing's disease: a systematic review. Clin Endocrinol (2014) 80(1):1-12. doi:10.1111/ cen. 12345

67. Bertagna X, Pivonello R, Fleseriu M, Zhang Y, Robinson P, Taylor A, et al. LCI699, a potent 11beta-hydroxylase inhibitor, normalizes urinary cortisol in patients with Cushing's disease: results from a multicenter, proof-of-concept study. J Clin Endocrinol Metab (2014) 99(4):1375-83. doi:10.1210/jc.2013-2117

68. Fleseriu M, Biller BM, Findling JW, Molitch ME, Schteingart DE, Gross C. Mifepristone, a glucocorticoid receptor antagonist, produces clinical and metabolic benefits in patients with Cushing's syndrome. J Clin Endocrinol Metab (2012) 97(6):2039-49. doi:10.1210/jc.2011-3350

69. Fleseriu M, Findling JW, Koch CA, Schlaffer SM, Buchfelder M, Gross C. Changes in plasma ACTH levels and corticotroph tumor size in patients with Cushing's disease during long-term treatment with the glucocorticoid receptor antagonist mifepristone. J Clin Endocrinol Metab (2014) 99(10):3718-27. doi:10.1210/jc.2014-1843

Conflict of Interest Statement: Dr. AL has an ownership interest in Kogent.

Copyright (c) 2016 Mooney, Simon and Little. This is an open-access article distributed under the terms of the Creative Commons Attribution License (CC BY). The use, distribution or reproduction in other forums is permitted, provided the original author(s) or licensor are credited and that the original publication in this journal is cited, in accordance with accepted academic practice. No use, distribution or reproduction is permitted which does not comply with these terms. 